Article - Smart Energy

\title{
Demand Manager for Energy Consumer with Local Storage and Microgeneration
}

\author{
Marcos Schreiber ${ }^{1}$ \\ https://orcid.org/0000-0001-8832-6002 \\ Lúcio de Medeiros ${ }^{1}$ \\ https://orcid.org/0000-0001-7075-8966
}

Zeno L. lensen Nadal ${ }^{2}$

https://orcid.org/0000-0001-6239-4488

\author{
Solivan A. Valente ${ }^{3}$ \\ https://orcid.org/0000-0002-6774-6099 \\ ${ }^{1}$ Institutos Lactec, Curitiba,Paraná, Brasil; ${ }^{2}$ COPEL Distribuição S.A., Curitiba, Paraná, Brasil, ${ }^{3}$ \\ Universidade Positivo, Curitiba, Paraná, Brasil
}

Received: 2018.11.05; Accepted: 2019.07.26.

* Correspondence: marcos@cidade300.com.br; lucio.medeiros@lactec.org.br; zeno.nadal@copel.com; solivan@up.edu.br

\begin{abstract}
The current reality of the energy market requires generation, control, distribution and consumption to become more efficient. Recent arrangements with electric energy stored in accumulators appear as strategic tools in the environment where the cost of energy supplied by the concessionaires and permission holders has accumulated successive increases, indirectly enabling the control and management of applications of micro or local minigeneration, from renewable sources in general. Systems with energy storage (e.g. batteries) and local demand management (many consumer units) achieve great efficiency by allowing the optimized consumption of the available energy, both by the local power grid and by the accumulated grid. Other advantages are presented for the distributors, allowing the relief of the electricity network, remunerating the investment in reduced intervals of time. Consideration should be given to the possibility of local autonomy, even if partially, by providing energy from the storage to the local loads in eventual failures in the supply of energy by the distribution network or at times where supply has a higher cost.

Keywords: Demand side management, energy storage, semi-autonomous microgeneration, intermittent microgeneration, renewable energy, minigeration.
\end{abstract}

\section{INTRODUCTION}

The management of electricity consumption increasingly has presented a major challenge, in particular the energy control and distribution, integrated with distributed generation (D.G), in addition to the need for its use to be more efficient [1]. The presence and importance of the use of renewable, clean and environmentally friendly sources increases, but mostly intermittent (such as solar and wind), introduces new challenges for a continuous energy supply. Many enterprises have already sought alternatives, not only to increase the generation of energy, but also to improve their production, seeking economic viability for new sources and in the improvement of their efficiency. In this scenario, a 
well-known element is at the forefront and becomes fundamental to address these new challenges: local energy storage, close to or near the end of consumption. Storing electrical energy in accumulators allows created control systems, both for a continuous supply, compensating for the intermittency of a local microgeneration (the case of most renewable sources), and for the supply of energy in the event of a power supply failure in the concessionaire network. The management of demand for consumer loads, in a scenario of continuous increase in the timeline, brings great efficiency to the consumption of all the energy available, both by the local and the accumulated electric grid [2]. In this case, a table of costs according to the time of day, considering the different tariffs, allows a more intelligent and efficient consumption through the use of accumulators, charging them in the hours of lowest cost and using them in the hours of high cost, with benefits for both sides of the power grid: the provider / distributor and the consumer.

Codemo; Ersegue; Zanella, (2013) claim that the use of large batteries in the end facilities and can reduce the average cost of power supply with this procedure, showing the direct impact of using batteries as a reducer of energy costs [3]. A system of local accumulation of electric energy guarantees the supply in times of eventual failures in the local supply, being normally dimensioned to supply the consuming loads for a certain period, classified as essential, however, it intrinsically compensates for the intermittency of microgeneration, if it is present [4]. It also becomes an agglutinating element of different sources of intermittent energy, including the local electrical network itself, only used in moments of low cost or when there is insufficient microgeneration and exhausted storage. It is important to remember that this type of consumer (called a prosumer, or prosumer, producer and consumer) mitigates new investments by energy concessionaires in the expansion of their generation and distribution systems, improving the load factor of their facilities.

\section{MATERIAL AND METHODS}

The microgeneration of electric energy at a consumption site can acquire different characteristics, depending on its connection to the loads and the local network. For renewable sources, it is necessary to have an energy converter element (for example, solar photovoltaic to electric), and a storage element, either a battery bank or any other type of energy accumulator.

In autonomous microgeneration (disconnected from any distribution network) all the energy produced is stored and consumed on the spot. In general, it is the only option for locations far from the distribution networks.

In connected microgeneration, the energy generated is consumed on site and any surplus is released into the distribution network, according to the established rules that allow the obtaining of energy credits, for the balance recorded at the end of each period [6]. The local electrical network performs the role of the storage element for intermittent generation, sometimes receiving and sometimes providing energy.

The chosen approach is developed in the third possibility: semi-autonomous microgeneration. Thus, in a qualitative way, by switching which of the available sources will be the energy provider for the charges occurs through a programmed microcontroller that monitors the status of the battery charge, directing the charges of the consumer unit in a staggered way for local accumulation, when this is sufficient, now for the local concessionaire, when this accumulation is insufficient [5].

This configuration requires the reversible switching of different loads in alternating current $(\mathrm{AC})$ and specific programming that monitors these two AC sources, possibly not synchronized with each other and with different wave forms. These three configurations described are shown in Figure 1, with emphasis on the last one, which is being proposed. 

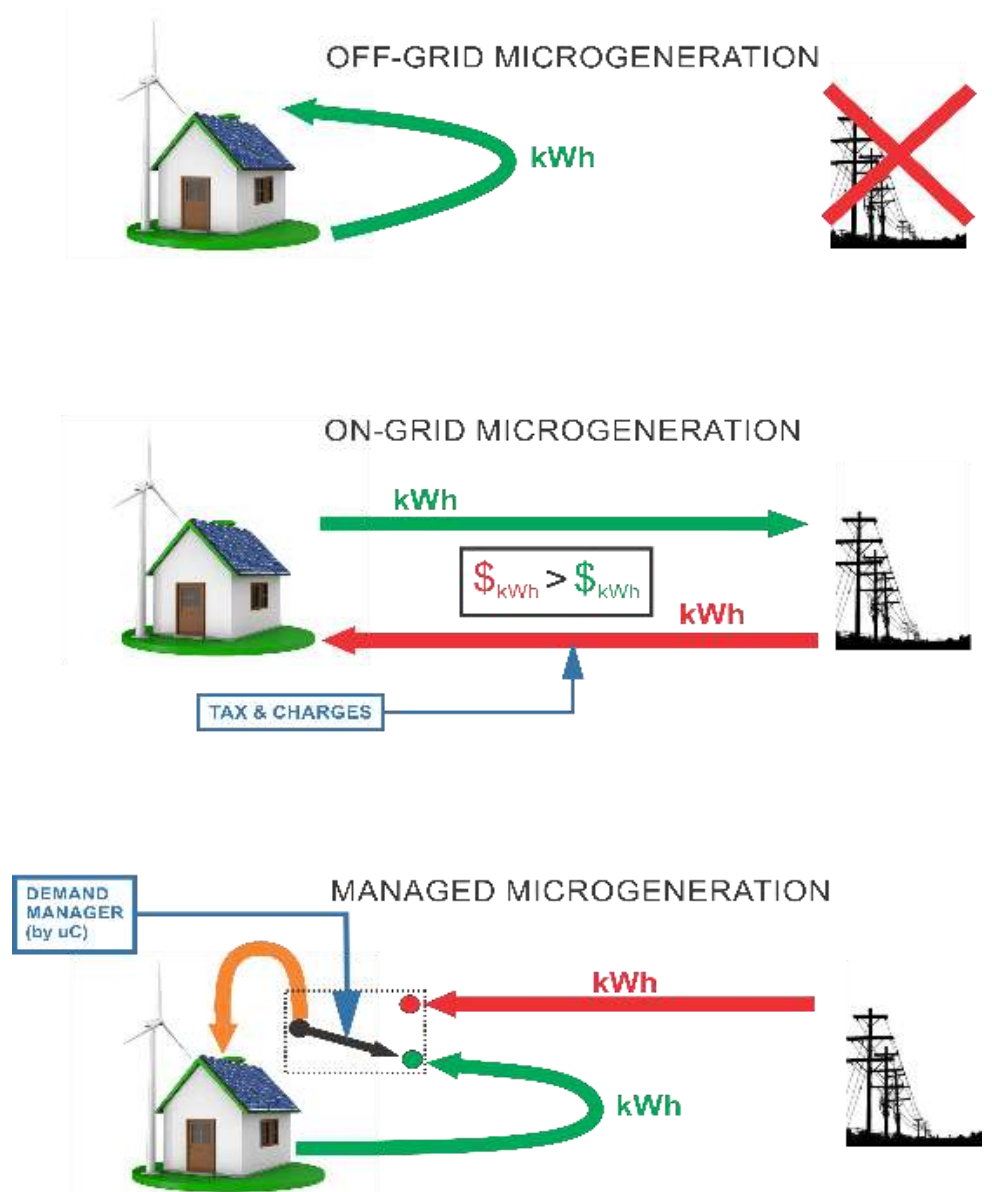

Figure 1 - Microgeneration Settings and the Semi-Autonomous Variation

The concept for this semi-autonomy is given by the reversible switching between generating sources: sometimes coming from the local concessionaire network, and sometimes coming from local microgeneration. It is one of the forms of what can be called a hybrid system. In this case, we use an off-grid inverter with a battery bank and a switch with relays and / or SSRs, triggered by a microcontroller with loT functionality. In a second step, a second inverter can be added, now of the on-grid type, to inject into the local network the surplus energy generated by local microgeneration, as one of the alternatives for the use of this surplus. In this semi-autonomous proposal, an element is developed to establish the control the demand for energy consumption, choosing the moments to revert between the accumulation itself and the local electric network, known here as Storage and Demand Manager [5]. It is observed that, at first, there is no injection of energy from microgeneration to the concessionaire electricity network, as it is directed to local consumption and storage.

The energy accumulation chosen was a lead-acid battery bank, due to its relatively low cost. It is noteworthy that these batteries can receive energy from local microgeneration as well as from the local utility grid, through an AC / DC converter, commanded by the $\mu \mathrm{C} /$ Manager, through a hierarchy programmed between these sources. As an example, in case of exceeding the established limit of discharge depth of the batteries, even with the AC loads already reversed to the local electrical network, then the AC / DC converter is activated by the $\mu \mathrm{C}$ / Manager, but when the cost of energy supplied is lower, contained in its own schedule, it can be updated through the query given by the loT (Internet of Things) functionality to the data network.

From the terminals of this battery bank, a DC Bus (direct current) can be conceptualized, more for schematic purposes than for its own physical existence, as a concentrating, storing and distributing element of energy, as shown in Figure 2 [5]. 


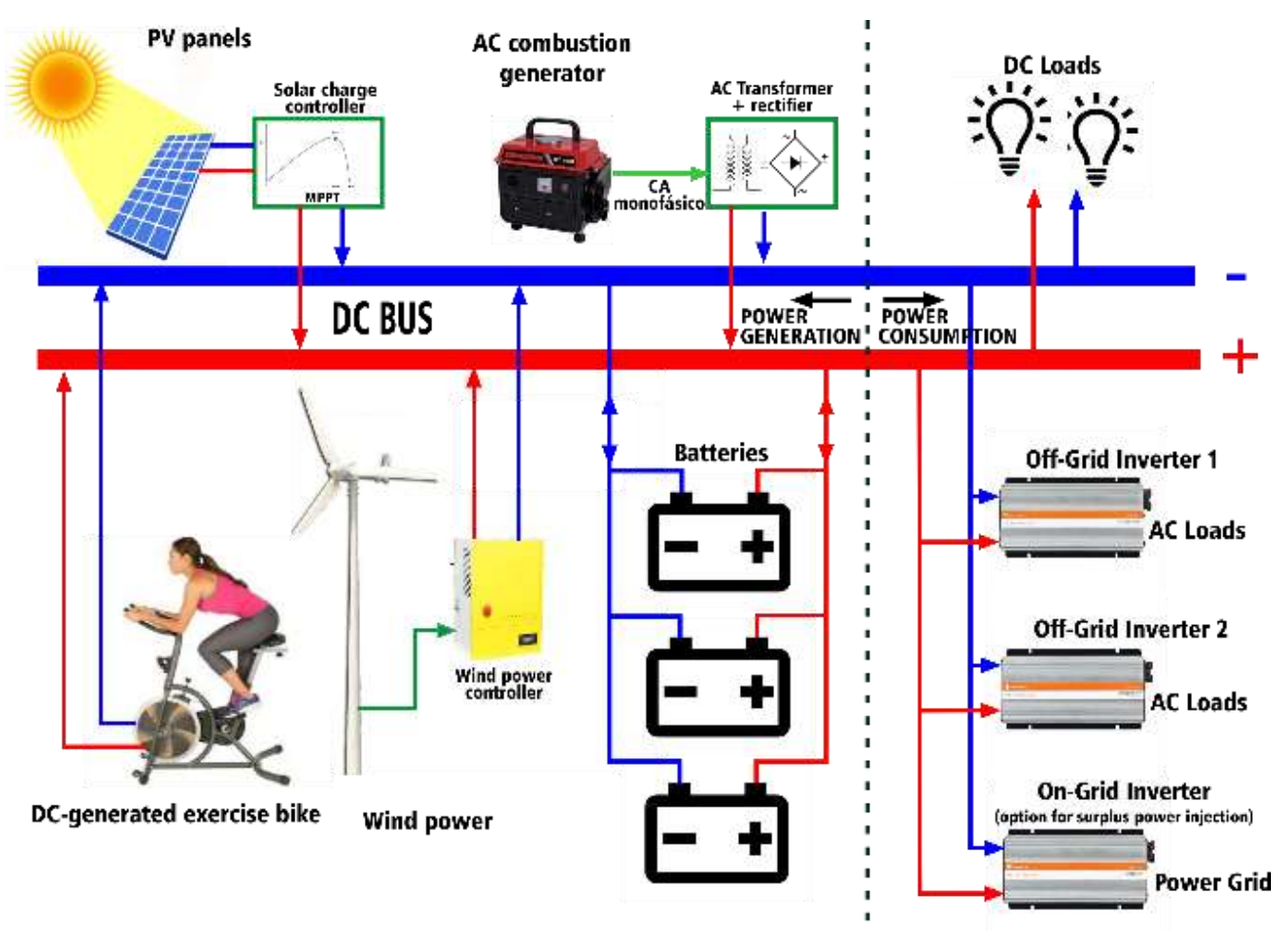

Figure 2 - DC Bus - Power Concentrator and Distributor

Some forms of microgeneration, if any, are connected to this bus, as well as energy consuming loads, either directly in DC or through DC / AC inverters. In this project there are two different inverters, one of the on-grid type, connected to the local concessionaire network, which will act only in moments of accumulated surplus energy and the other of the off-grid type, which will act continuously, ensuring supply to the loads of consumers in AC (alternating current) that are reversed by the Manager, even in times of supply failure in the local concessionaire network. The Manager, monitoring the battery charge situation, will add more AC loads to this inverter, removing them from the local power grid, or removing them from it by putting them back into the power grid. This load reversal process is carried out by switching at moments of complete $\mathrm{AC}$ sync between the sources in question, allowing a minimum load time without current, if relays are used, or null if SSRs are used. This happens through the element called Multichannel AC Switch. In this project it foresees the reversibility of up to eight channels, that is, up to eight sets of AC loads. In the example of microgeneration using solar panels, the demand management of these loads in an already implemented system of three channels (LIGHT, MEDIUM and COMPLEMENTARY loads) is shown in Figure 3, for a day full of sunshine. 


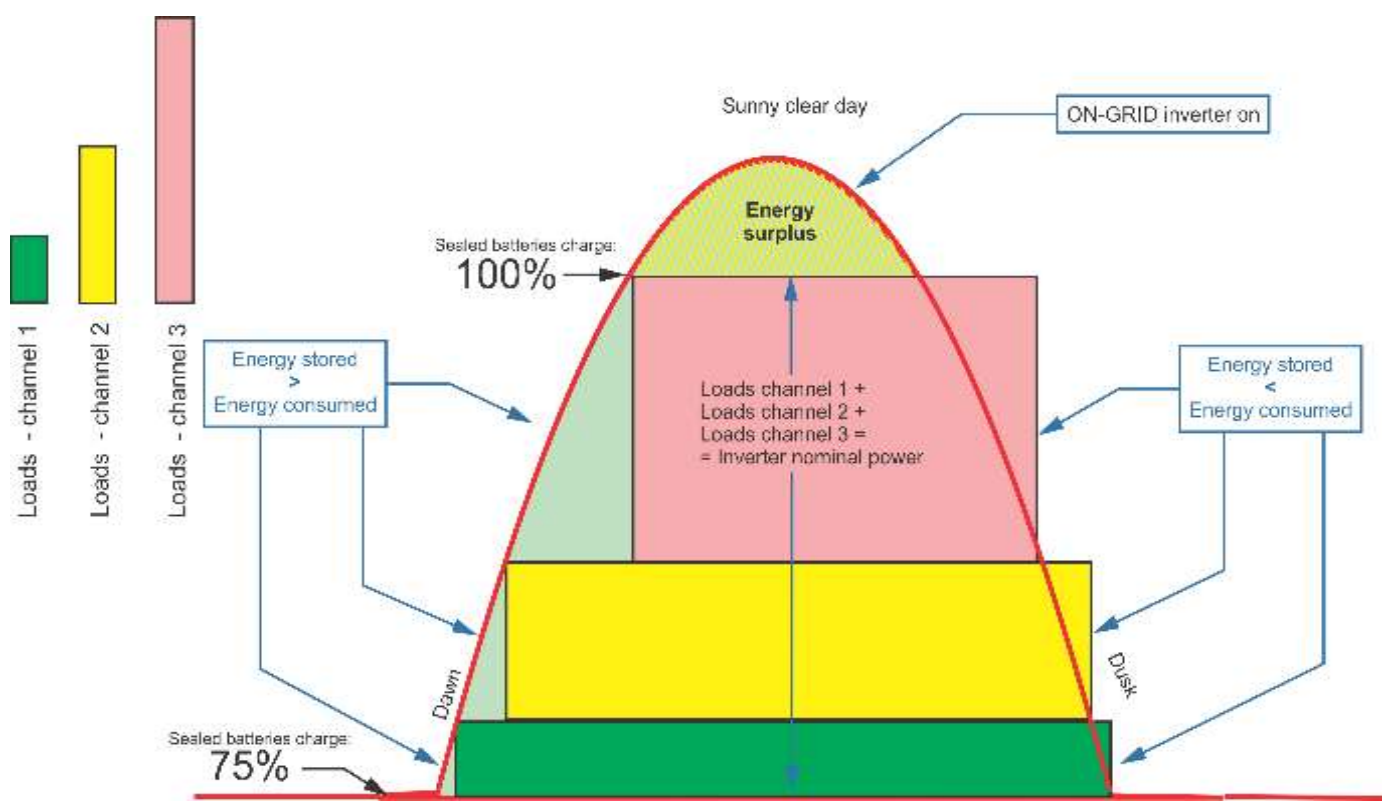

Figure 3 - Demand Management for a Total Sunset Day - 3 Consumer Branches

Even though the three switching channels assign different sources of energy to their loads, two more channels can still be considered: Essential loads, of low consumption, such as LED lighting for example, can be permanently connected to the storage, through the DC inverter / AC or directly to the DC bus, if possible. On the other hand, non-essential loads of high consumption can be permanently connected to the local utility network, thus avoiding a high cost of storage, microgeneration and inverters to provide them with energy, an important issue in the cost of hybrid systems.

It is observed that, from dawn until sunstroke it produces energy to bring the battery charge to $100 \%$, whereby the energy is stored and consumed at the same time. As the loads are superimposed on the inverter by the demand manager, more energy is consumed. In the reverse process, as the insulation decreases, in the evening, for example, the charges are reversed back to the local network, until they reach a pre-established value here of $75 \%$ of the charge in the batteries, which will thus supply energy not only to the essential loads permanently connected to the inverter, but also to all the others when the local network fails, because in this case the manager will quickly pass them on to the inverter.

For a day with varying cloudiness, the Demand Manager may behave as shown in Figure 4. The loads are gradually placed and removed from the microgeneration, as the day's heat varies. It is important to remember that, for a greater efficiency of this project, the accumulated surplus energy can be injected into the local concessionary network, through a second inverter, of the on-grid or grid-tie type, by means of the necessary contract and approvals. 


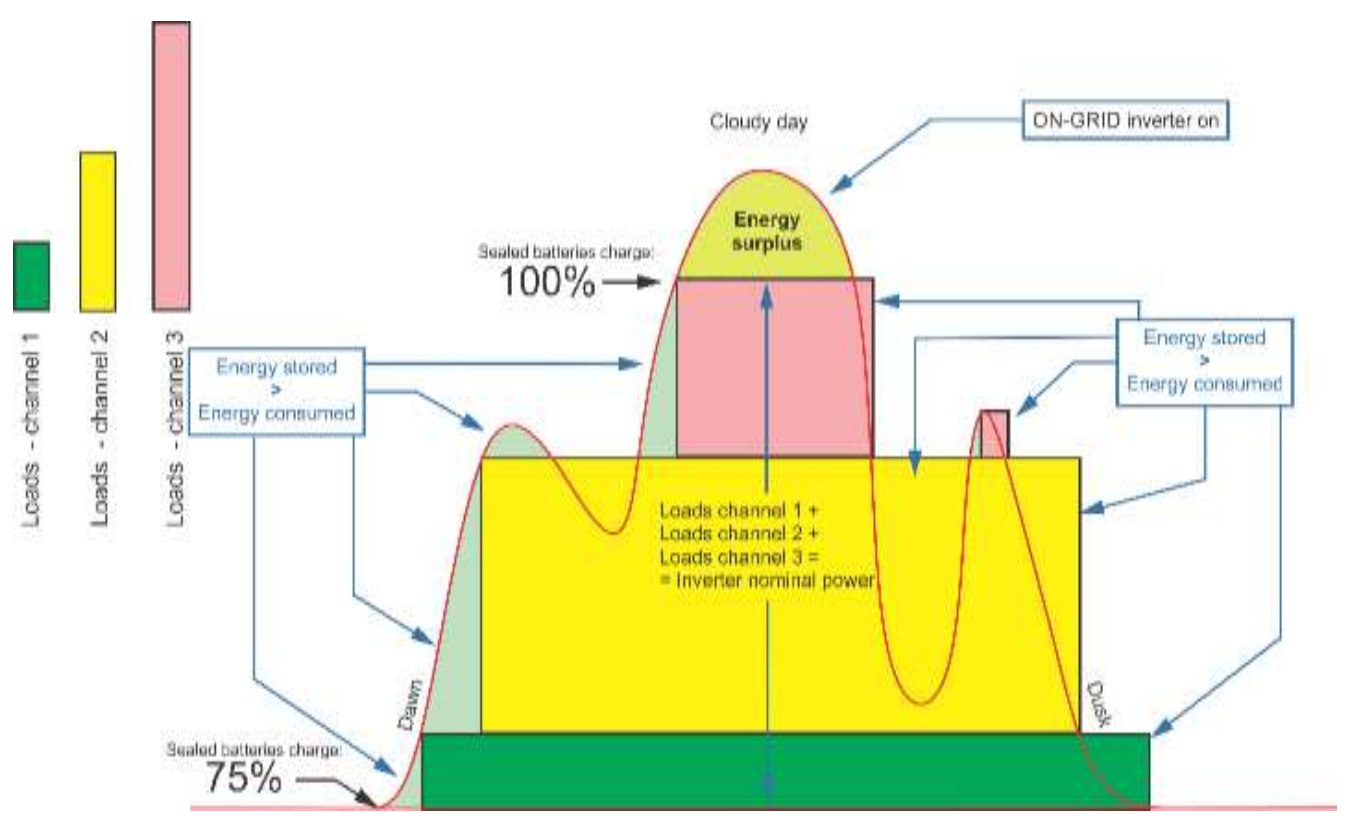

Figure 4 - Demand Management for a Cloudy Day - 3 Consumer Branches

Essentially, this semi-autonomous system seeks the greatest possible savings in addition to partial or total autonomy. It allows the use of intermittent and renewable sources of energy, which can be customized to the consumer's profile, simultaneously.

For the purposes of an operational and quantitative methodology, a low cost programmable microcontroller (open source, from the Arduino series) was used in this management, which can be adapted to the generation and consumption profile of the user, and programmed to act on the demand control, performing the reversals as shown in Figure 5. The choice of source that the loads will be supplied is made based on the monitoring of the batteries, among other parameters.

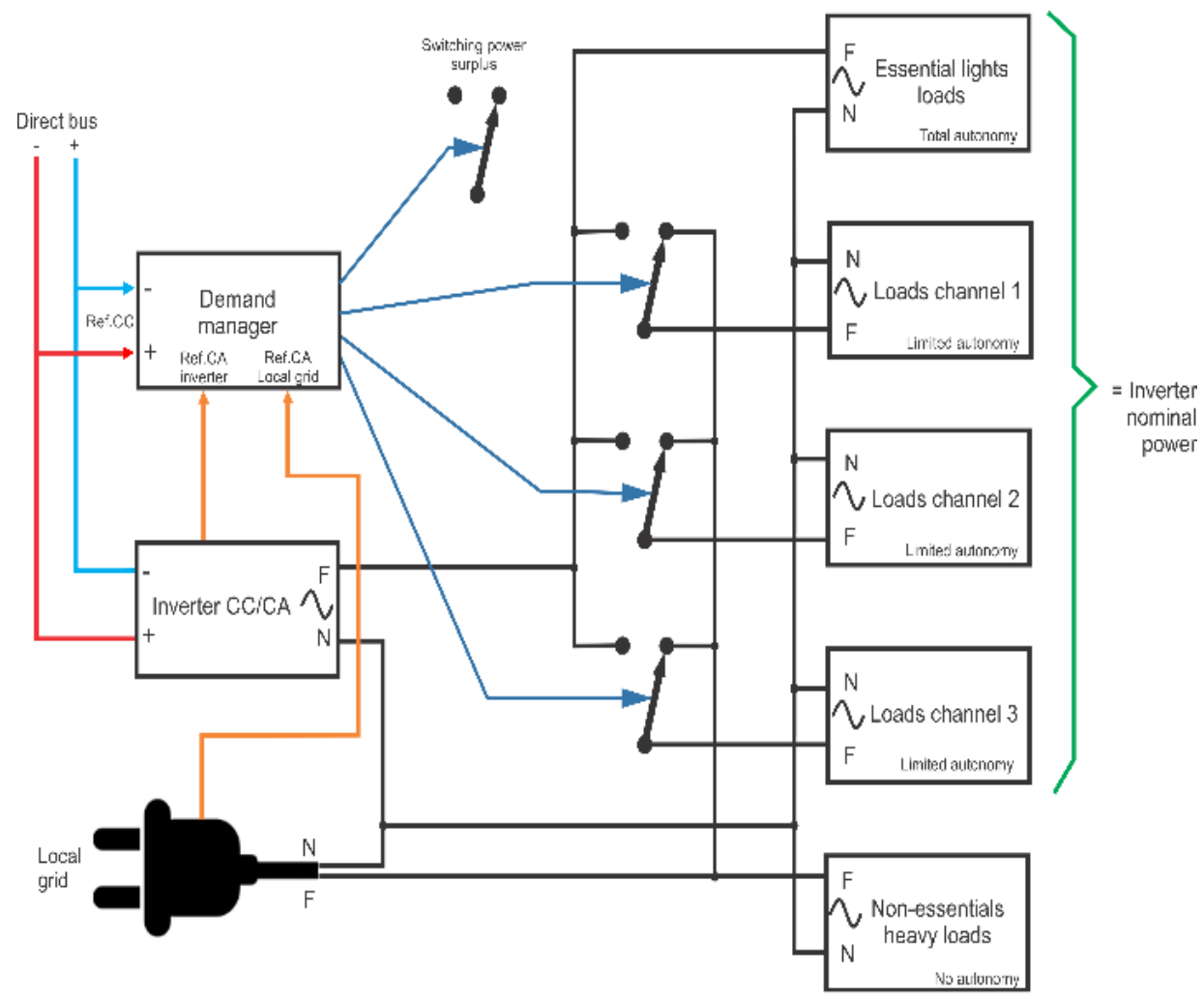

Figure 5 - Distribution of Loads for Demand Management 
Compared to an on-grid photovoltaic system, the installation is slightly more complex, as it requires an expressive intervention in the energy distribution framework and may be installed in home automation installations. The microcontroller programming also allows the choice of essential loads that will remain connected primarily to batteries. All decisions are made by indirect measurement of power generation in the DC bus for a predetermined period. It is indirect, because from the measurement of the voltage on the bus, the percentage of the charge of the batteries is calculated. Thus, there is always a consolidation of values that represent what is being generated and consumed. The second step, after the decision is taken, is the switching (reversing) of these loads, from one source to another, in a very precise process that minimizes any surge of current and sparking in the relay contacts, as it seeks the moment of phase synchronization to perform this switching. The photovoltaic solar generation injects its energy into the DC bus through the MPPT charge controller (maximum power point tracking). Usually this type of control is built into the inverter itself, as well as the AC / DC charger (in the case of OFF-GRID inverters) that is connected to the power grid and is only activated when the batteries are deeply discharged.

This system can operate with any type of DC / AC inverter or generator, considering their non-synchronism with the local network in a common situation. Thus, the developed programming seeks the timing of the $\mathrm{AC}$ sources exactly at the zero-voltage output transient and the beginning of the upward wave of the two sources. If the inverter is of the type that is synchronized with the local AC network, then there is no waiting for the reversal, it takes place immediately. With the use of SSRs (Solid State Relays), this reversal occurs when the signal passes through zero in the generation in alternating current, so that the time that the load will be without current is zero. In the case of disconnected loads, the area of the available energy curve expands considerably. For this reason, it was considered as a hybrid solution, already foreseen in the demand manager's programming that drives an on-grid inverter and injects the surplus into the local distribution network. A version of the electronic assembly was divided into three parts: switch, microcontroller and AC / DC source, as shown in Figure 6

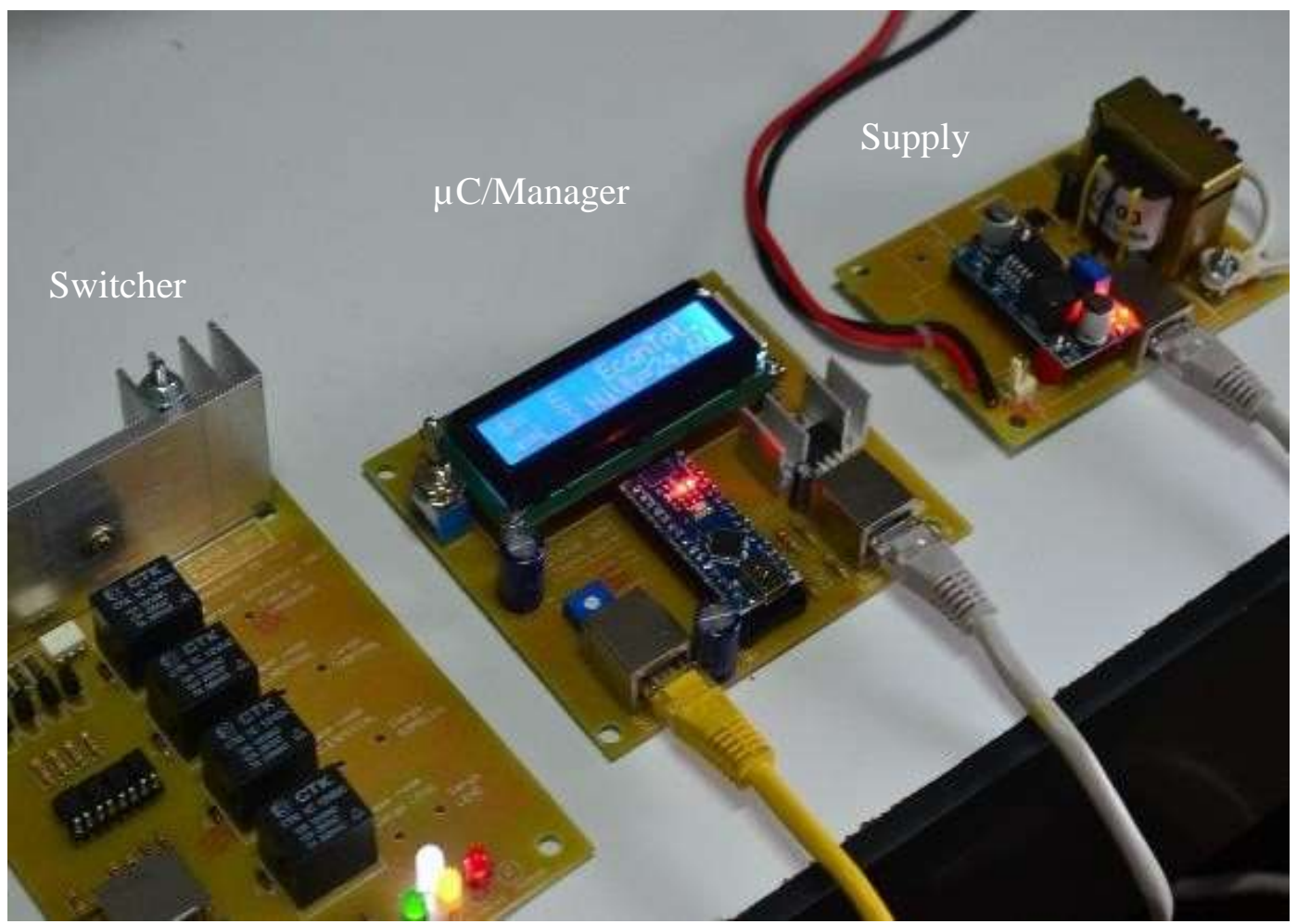

Figure 6 - A Version of the Electronic Assembly 


\section{RESULTS}

Among the results achieved, an average saving from 190 to $245 \mathrm{kWh}$ per month can be highlighted, that is, savings from $42 \%$ to $54 \%$, in a system of $1,320 \mathrm{Wp}$ in photovoltaic panels, a 300W wind generator, a 350W gasoline and an exercise bike with 200W DC generator, installed in a residence in Curitiba, Paraná, whose average consumption is 450 $\mathrm{kWh}$ per month. The savings statistics obtained were performed over a period of 28 months, passing through all seasons, also raising the parameters of behavior of the battery bank.

\section{DISCUSSION}

This system is essentially hybrid, bringing savings and autonomy to the consumer. The savings generated are due to what is no longer consumed by the local concessionaire network. Only in moments of surplus energy will there be an exchange with the injection into the local network, now accounted for in monetary cost of the generated and consumed kWh. This is the main difference of a common connected photovoltaic generation, as it reduces the disadvantage given by the unilateral taxation in the accounting for energy exchange. The other, not less relevant, is the autonomy, even if partial, that happens in moments of power supply failure in the concessionaire network. This represents an important cost to be considered, especially for an economic activity that depends on electricity. Demand management is already well known and consolidated. The proposal here is based on a decision to monitor local storage with reversible switching between the local network and the energy stored by microgeneration and / or by the local electrical network.

\section{CONCLUSION}

This project proposes the optimization of efficiency in the use of intermittent sources of renewable energy, allowing such sources to be simultaneously connected, such as a small local microgrid with optimal demand control. Even though it is semi-autonomous, the system also operates in complete autonomy, enabling itself even in remote locations or with little availability of distribution networks. Compared with a hybrid system, which requires storage and generation capacity that supports the entire load, in addition to a precise and large switching, necessary for the islanding situation, this project works on pre-qualified loads in its installation, allowing both microgeneration and storage to be dimensioned only for loads qualified as essential. With batteries increasingly efficient and, in a large-scale production, and cheaper, the installations are becoming more viable. The possibilities created can progress more, allowing broad control within the concept of Smart grids, making use of loT microcontrollers with large-scale integration of intelligent distributed energy storage systems (Virtual Power Plants).

Acknowledgments: The authors are particularly grateful for the technical support provided in the R\&D Project 02866-0442 / 2016, by the LACTEC Institutes and COPEL Distribuição S.A., in the scope of ANEEL's R\&D program.

\section{REFERENCES}

1. Barsali, S. et al. Storage applications for Smart grids. Electric Power Systems Research, v. 120, p. 109-117, 2015.

2. Choi, J. et al. Robust Control of a Microgrid Energy Storage System using Various Approaches. IEEE Transactions on Smart Grid, p. 1-1, 2018.

3. Codemo, C. G.; Erseghe, T.; Zanella, A. Energy storage optimization strategies for smart grids. IEEE International Conference on Communications. Anais...2013

4. HINRICHS, R. A.; KLEINBACH, M.; REIS, L. B. DOS. Energy and environment. Ed. New York: Cengage Learning, 2018. 
5. SCHREIBER, M.; CANETTA, A.; FROSSARD, A. Demand control for semi-autonomous micro-generation, with intermittent and renewable energy sources (M. Schreiber, A. T. Canetta, A. Frossard, Eds.). Curitiba, Paraná, Brazil: Universidade Positivo, 2018.

6. ZHENG, M.; MEINRENKEN, C. J.; LACKNER, K. S. Agent-based model for electricity consumption and storage to evaluate economic viability of tariff arbitrage for residential sector demand response. Applied Energy, v. 126, p. 297-306, 2014.

(C) (7) (5) 2018 by the authors. Submitted for possible open access publication BY NC BY NC) license (http://creativecommons.org/licenses/by-nc/4.0/). 